\title{
Compared to Australian Cultivars, European Summer Wheat (Triticum aestivum) Overreacts When Moderate Heat Stress Is Applied at the Pollen Development Stage
}

\author{
Kevin Begcy ${ }^{1}$ (i) , Anna Weigert ${ }^{1}$, Andrew Ogolla Egesa ${ }^{1,2}$ and Thomas Dresselhaus ${ }^{1, *}$ (i) \\ 1 Cell Biology and Plant Biochemistry, Biochemie-Zentrum Regensburg, University of Regensburg, \\ 93053 Regensburg, Germany; kevin.begcy@ur.de (K.B.); Anna.Weigert@stud.uni-regensburg.de (A.W.); \\ andrew-ogolla.egesa@stud.uni-regensburg.de (A.O.E.) \\ 2 Department of Biochemistry and Biotechnology, Kenyatta University, Nairobi 2 0142, Kenya \\ * Correspondence: thomas.dresselhaus@ur.de
}

Received: 2 May 2018; Accepted: 12 June 2018; Published: 26 June 2018

\begin{abstract}
Heat stress frequently imposes a strong negative impact on vegetative and reproductive development of plants leading to severe yield losses. Wheat, a major temperate crop, is more prone to suffer from increased temperatures than most other major crops. With heat waves becoming more intense and frequent, as a consequence of global warming, a decrease in wheat yield is highly expected. Here, we examined the impact of a short-term $(48 \mathrm{~h})$ heat stress on wheat imposed during reproduction at the pollen mitosis stage both, at the physiological and molecular level. We analyzed two sets of summer wheat germplasms from Australia (Kukri, Drysdale, Gladius, and RAC875) and Europe (Epos, Cornetto, Granny, and Chamsin). Heat stress strongly affected gas exchange parameters leading to reduced photosynthetic and transpiration rates in the European cultivars. These effects were less pronounced in Australian cultivars. Pollen viability was also reduced in all European cultivars. At the transcriptional level, the largest group of heat shock factor genes (type A HSFs), which trigger molecular responses as a result of environmental stimuli, showed small variations in gene expression levels in Australian wheat cultivars. In contrast, HSFs in European cultivars, including Epos and Granny, were strongly downregulated and partly even silenced, while the high-yielding variety Chamsin displayed a strong upregulation of type A HSFs. In conclusion, Australian cultivars are well adapted to moderate heat stress compared to European summer wheat. The latter strongly react after heat stress application by downregulating photosynthesis and transpiration rates as well as differentially regulating HSFs gene expression pattern.
\end{abstract}

Keywords: wheat; heat stress; heat shock factors (HSF); pollen mitosis; pollen viability; gas exchange parameters; photosynthesis; transpiration

\section{Introduction}

Wheat (Triticum aestivum) is one of the three major cereal crops, which contributes to more than $20 \%$ of the total human caloric and protein intake worldwide [1]. The first evidence of wheat domestication dated of about 12,000 years ago in the Middle East contributing to the transition from hunting and gathering of food to settled agriculture during human civilization [2,3]. Since then, wheat plants have been cultivated in a wide range of climatic conditions and in many geographic regions. Currently, Australia and Europe are two main hubs for wheat production. A large degree of heat stress resilience has been identified within Australian cultivars, with a significant number of cultivars exhibiting high levels of tolerance [4]. Australian wheat production has increased largely as a 
result of improved cultivars and well established crop management practices. In Europe, together with maize, barley, and rye, wheat is one of the main agricultural crops. European wheat production represents around $20 \%$ of the total production worldwide [5]. However, largely attributed to climate conditions, a decrease in total cereal production has been observed in European countries over the past two decades [6].

Wheat adaptation to the Australian environment started more than 200 years ago, when the First Fleet arrived to Sydney around 1788 [7]. The first evidence of a successful cross-breeding employing a European cultivar (Italian wheat Tuscan) in Australia dated back to 1860 [7]. Since then, two major events have defined the evolution of the Australian wheat germplasm. First, the introduction of earlier flowering material and second the use of semi-dwarf germplasm during the early $70 \mathrm{~s}$ of the last century [7]. In Europe, wheat breeding has a longer history, since it was spread from the Middle East to the entire European continent, first via Greece and then through the Danube river and the Balkans to Northern Europe [2]. Different breeding strategies have been employed in Europe depending on specific interests and market requirements. For instance, highly productive British wheat varieties with low tolerance to climate conditions have been crossed with high yielding German lines to develop varieties better adapted to increased temperatures with higher productivity [8]. However, even though some progress has been made with European varieties, long-term climate adaptation of Australian wheat varieties during breeding have generated genetic pools more resilient to environmental stresses compared to their European counterparts.

Gas exchange parameters, especially photosynthetic and transpiration rates, are particularly sensitive to heat stress [9]. Studies in wheat, rice, and tomato have shown that high temperatures lead, for example, to deactivation of the key $\mathrm{CO}_{2}$-fixating enzyme RUBISCO [10,11], which correlates with a decline in photosynthesis observed at higher temperatures [12-14]. Therefore, maintenance of photosynthetic activity as well as high transpiration rates are considered indicators of heat tolerance. Furthermore, at the molecular level, heat shock factors (HSFs) are important regulators during plant response to increased temperatures. HSFs have been described as inducible transcriptional regulators of numerous genes encoding-for instance, molecular chaperones, ion transporters, aquaporins, and other stress proteins-in order to regulate stress responses. Moreover, HSFs have been shown to be master regulators for triggering acquired thermotolerance and heat stress responses $[15,16]$. In wheat, HSFs have been categorized into three groups [17], of which type A represents the largest group containing some gene members that are specifically expressed during reproductive development.

At the reproductive stage, heat stress results in severe yield losses in several crop species including wheat [18-21]. Particularly, male reproductive development is sensitive to environmental stresses [18,22]. Elevated temperatures during pollen development are detrimental to the formation of functional pollen. Anthers and pollen itself represent important photosynthetic sink tissues as high accumulation of photoassimilates, including starch and monomers of carbohydrates, are required during their development $[18,22]$. Starch and other reserve substances are accumulated in pollen grains and required during pollen tube growth to deliver the sperm cells towards the female gametes (egg and central cell) to ensure proper fertilization. Thus, disruption of pollen development or decrease in nutrient supply is expected to lead to sterility and failure of seed set, which potentially results in yield decrease.

Our current understanding of pollen development is mainly derived from model species such as maize, rice, and Arabidopsis [23-25]. Male gametophyte development (pollen) in wheat is poorly characterized, and even less is known how environmental stresses impact pollen development at the physiological and molecular level in this species. In wheat, studies associated with pollen susceptibility to heat stress are scarce [26-29] and were not performed under highly controlled moderate environmental stress conditions, allowing to separate heat stress from other stresses. Most studies have been focused on grain yield and quality [30,31]. Physiological and molecular parameters were usually not investigated, thus the mechanisms underlying reduced pollen viability, an important yield component, remained unexplored. 
Understanding the effect of heat stress in two contrasting germplasms will help to mitigate the impact of increased temperature on wheat performance. With the goal to understand the adaptation of Australian summer wheat cultivars and the susceptibility of European cultivars to moderate heat stress, we selected four cultivars of each germplasm and compared them by measuring transpiration and photosynthetic rates, viability of male reproductive structures, and the response in gene expression levels of type A HSF genes. In the long term, this study may contribute to the development of an improved European germplasm with enhanced resilience to increased temperatures.

\section{Materials and Methods}

\subsection{Plant Growth Conditions and Heat Stress Treatment}

Wheat cultivars from Australia (Triticum aestivum L. cv. Kurki, Drysdale, Gladius, and RAC875) and Europe (Triticum aestivum L. cv. Epos, Cornetto, Granny, Chamsin) (Table 1) were germinated in an incubator and then transferred to pots $(10 \mathrm{~cm}$ diameter, two seedlings per pot) containing a mixture of $15 \%$ sand, $25 \%$ Liapor (swelling clay), and 60\% substrate (Einheitserde). Ten seedlings of each cultivar in each of three independent experiments were then transferred to $10 \mathrm{~L}$ pots to the greenhouse under controlled conditions of $14 \mathrm{~h} \mathrm{~L} / 10 \mathrm{~h}$ dark photoperiod, with $21^{\circ} \mathrm{C} \pm 2{ }^{\circ} \mathrm{C}$ daytime temperature and $18{ }^{\circ} \mathrm{C} \pm 2{ }^{\circ} \mathrm{C}$ night temperature, and a constant air humidity of $60-65 \%$. An automated temperature-water based irrigation system was used to supply water according to plant consumption in a time-based pre-programmed schedule. Plants were fertilized twice a week with $2 \%$ fertilizer (Hakaphos) and monitored throughout their entire vegetative and reproductive developmental stages. After spikes developed, the auricle distance (the distance between the auricles of the flag leaf and the second last leaf) of each spike was measured. Spikes with auricle distance between 13-15 cm were marked and used for heat stress experiments; at this stage wheat plants enter pollen mitosis [32]. Spikes with an auricle distance of different lengths were not considered. Plants at pollen mitosis were then transferred to walking growth chambers. Non-heat-stressed control plants were maintained in chambers with identical conditions as described above. For heat stress, temperatures during the light/dark photoperiod were increased to $35^{\circ} \mathrm{C} / 25^{\circ} \mathrm{C}$, respectively, but otherwise conditions remained unchanged. Plants were kept for $48 \mathrm{~h}$ under heat stress conditions and then directly analyzed.

Table 1. List of summer wheat varieties (all bread wheat) used in this study. Their respective country of origin and flowering time are indicated.

\begin{tabular}{ccc}
\hline Variety Name & Country of Origin & Flowering Time \\
\hline Kukri & Australia & $40 \pm 1$ day \\
Drysdale & Australia & $48 \pm 1.5$ days \\
Gladius & Australia & $49 \pm 1.8$ days \\
RAC875 & Australia & $45 \pm 2.3$ days \\
Epos & Czech Republic & $52 \pm 2.4$ days \\
Cornetto & Germany & $57 \pm 1.1$ days \\
Granny & Czech Republic & $50 \pm 1.6$ days \\
Chamsin & Germany & $53 \pm 2$ days \\
\hline
\end{tabular}

\subsection{Physiological Measurements}

Wheat plants of Australian and European cultivars were continuously monitored during the time course of the experiments. Gas exchange parameters were recorded at 0,24 , and $48 \mathrm{~h}$ in control and heat stressed plants. Fully expanded flag leaves were used to estimate net photosynthetic rate (A) and transpiration rate (E). Daily measurements were taken with an Infrared Gas Analyzer (IRGA, LCpro+; ADC Bioscientific, Hoddesdon, UK) at a $\mathrm{CO}_{2}$ concentration of $360 \mu \mathrm{L} \mathrm{L}^{-1}$, a saturating light intensity of $1000 \mu \mathrm{mol} \mathrm{m}^{-2} \mathrm{~s}^{-1}$ and a gas flow rate of $200 \mathrm{~mL} \mathrm{~min}^{-1}$ as described before [33-35]. For each time point, 15 to 20 plants per treatment were examined and measurements completed between 10:30 a.m. and 2:00 p.m. Data were recorded when gas exchange and chlorophyll fluorescence parameters became stable during measurements. 


\subsection{Histological Analysis}

Anthers of non- and heat-stressed plants were fixed in 3.7\% $(w / v)$ formaldehyde, $5 \%(v / v)$ acetic acid and $50 \%(v / v)$ ethanol, vacuum infiltrated, and stored at $4{ }^{\circ} \mathrm{C}$ overnight. Samples were then embedded in $10 \%(w / v)$ low melting agarose dissolved in distilled water. Samples were kept in gelatine blocks and post-fixed with $10 \%$ formaldehyde and $0.1 \mathrm{M}$ standard PBS buffer at $4{ }^{\circ} \mathrm{C}$ overnight. Embedded blocks $(1.5 \times 1.5 \times 1.0 \mathrm{~cm})$ were stored at $4{ }^{\circ} \mathrm{C}$ in PBS until sectioning. Cross-sections $(60 \mu \mathrm{m}$ thick) were prepared using a vibratome Hyrax V50 (Carl Zeiss MicroImaging, Thornwood, NY, USA). For quality comparisons, at least 10 cross sections were prepared per sample. Three independent experiments were each performed to collect anthers for sectioning. Images of anther sections shown in Figure S1 are representatives of observations across replicates.

\subsection{Microscopy and Pollen Viability Assay}

Mature pollen grains of non- and heat-stressed wheat of all eight cultivars were isolated and mounted on glass slides containing $3.33 \mathrm{~g} / \mathrm{L}$ iodine and $6.66 \mathrm{~g} / \mathrm{L}$ potassium iodide, covered with a cover slip and observed in a Zeiss Axio Imager Z1 microscope equipped with an apotome module and an AxioCam MRM monochromatic camera. We tested on average three thousand grains per cultivar/condition.

\section{5. $R N A$ Isolation and $R T-q P C R$}

Total RNA from pollen was isolated using the RNA Plant Mini kit (Ambion, Waltham, MA, USA) following the manufacturer's instructions. cDNA synthesis was performed using reverse transcriptase (Invitrogen SuperScript II, Carlsbad, CA, USA) and oligo(dT) primers. Real time PCR reactions were performed using KAPA SYBR Fast qPCR master mix (Peqlab Biotechnology, Erlangen, Germany) as described [25,35]. Expression levels of a wheat tubulin gene (GenBank accession No. U76558) were used as internal standards for normalization of cDNA template quantity using tubulin-specific primers (Table S1). PCRs were performed using a MasterCycler ${ }^{\circledR}$ RealPlex ${ }^{2}$ system (Eppendorf, Hamburg, Germany) in a 96-well reaction plate according to the manufacturer's recommendations. Primers used in this study are listed in Table S1. Cycling parameters consisted of 5 min at $95^{\circ} \mathrm{C}$, and 40 cycles at $95^{\circ} \mathrm{C}$ for $15 \mathrm{~s}, 60^{\circ} \mathrm{C}$ for $30 \mathrm{~s}$, and $70{ }^{\circ} \mathrm{C}$ for $30 \mathrm{~s}$ as described previously [24]. qPCR reactions were performed in triplicate for each RNA sample on at least three biological replicates. Specificity of the amplifications was verified by a melting curve analysis to test product specificity. Results from the MasterCycler ${ }^{\circledR}$ RealPlex2 detection system were further analyzed using Microsoft Excel. Relative amounts of mRNA were calculated from threshold points (Ct values) located in the log-linear range of real time PCR amplification plots using the $2^{-\Delta \mathrm{Ct}}$ method [36].

\subsection{Statistical Analysis}

Statistical analyses were performed using the R software/environment. A one-way ANOVA was used to compare flowering time between Australian and European cultivars. Data from at least three independent experiments, where each experiment had at least $n=6$ plants per cultivar/condition were used. Data were expressed as means with standard deviation, and $p$-value of 0.05 was used as the significance level.

\section{Results}

Eight Australian and European summer wheat cultivars (Table 1) were exposed to a moderate heat stress $\left(35^{\circ} \mathrm{C}\right.$ during the day and $25^{\circ} \mathrm{C}$ during the night) for $48 \mathrm{~h}$ after flowering induction when anthers contained pollen at the mitosis stages of development. Flowering time was significantly shorter in all-Australian cultivars compared to the European varieties. Our experimental design aimed to reflect short heat temperature episodes, which are very frequent in Europe as a consequence of global warming. 


\subsection{Physiological Responses of Australian and European Summer Wheat Cultivars under Heat Stress}

\subsubsection{Transpiration Rate Was Strongly Reduced in European Cultivars}

Since heat stress events lead to damaging the photosynthetic apparatus and withering of plants [37], we first compared gas exchange parameters between Australian and European wheat cultivars. We measured the transpiration rate at the beginning of the experiment $(0 \mathrm{~h})$ as well as 24 and $48 \mathrm{~h}$ after heat stress (HS). A control group of non-stressed plants was measured in a neighboring growth chamber at the same time-points. Apart from the temperature, all other conditions were kept constant. Transpiration rates in the Australian varieties Kukri and Gladius, remained comparable in both HS and control conditions (Figure 1A,G). Phenotypically, these cultivars appeared unchanged even $48 \mathrm{~h}$ after HS treatment (Figure 1B,C,H,I). Plants looked healthy, showed almost no sign of stress with only a few curled leaves. In the varieties Drysdale and RAC875, a decrease in transpiration rates was observed $24 \mathrm{~h}$ after HS (Figure 1D,E) and a further reduction was noticed after $48 \mathrm{~h}$ of $\mathrm{HS}$. However, transpiration rates were still significantly above a 50\% level of the non-stressed control plants. These cultivars also looked healthy, though RAC875 showed partly yellowish leaves and a larger number of curly leaves compared with the other Australian varieties.

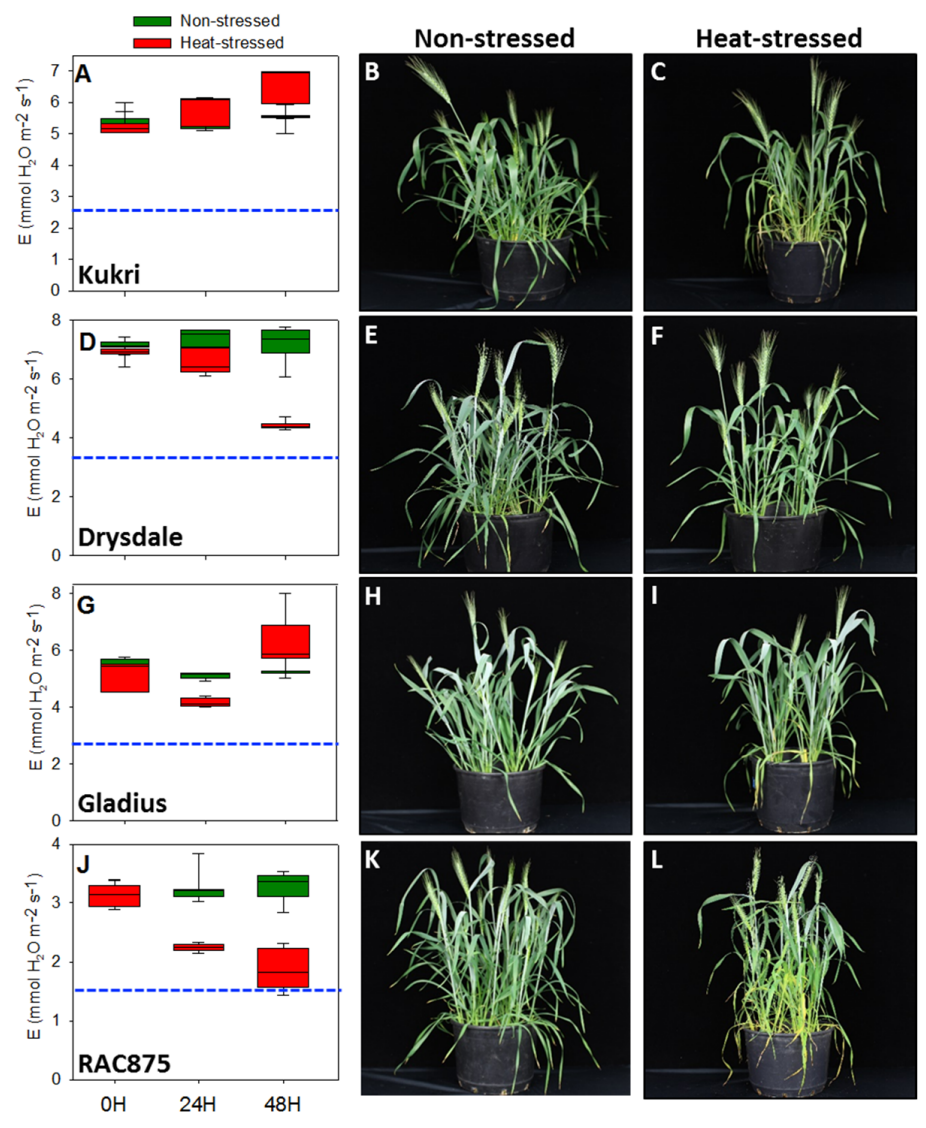

Figure 1. Transpiration rate is maintained under moderate heat stress by Australian summer wheat varieties. Physiological and phenotypical effects on varieties Kukri (A-C), Drysdale (D-F), Gladius (G-I), and RAC875 (J-L) are shown. Box plots show the central tendency and dispersion of the transpiration rate among all Australian cultivars. Green and red box plots represent non- and heat-stressed plants, respectively. Blue bars show 50\% transpiration rate of non-stressed plants. 15-20 plants of each line were examined.

In contrast, the European summer wheat cultivars showed a pronounced decline in transpiration rate after HS imposition (Figure 2). With the exception of the cultivar Chamsin, elevated temperatures 
resulted on average in a $25 \%$ reduction of transpiration rates in European cultivars after $24 \mathrm{~h}$ of $\mathrm{HS}$. After $48 \mathrm{~h}$ of HS, all cultivars showed a reduction in transpiration rates close to $75 \%$ and in some instances even higher as observed in Epos (Figure 2A,D,G,J). This effect was confirmed phenotypically, as heat-stressed plants wilted and showed yellowish leaves (Figure 2). In summary, Australian cultivars showed a higher tolerance to moderate heat stress indicated by their appearance and sustained high levels of transpiration rates. European lines were less tolerant and showed a marked reduction of transpiration rate.
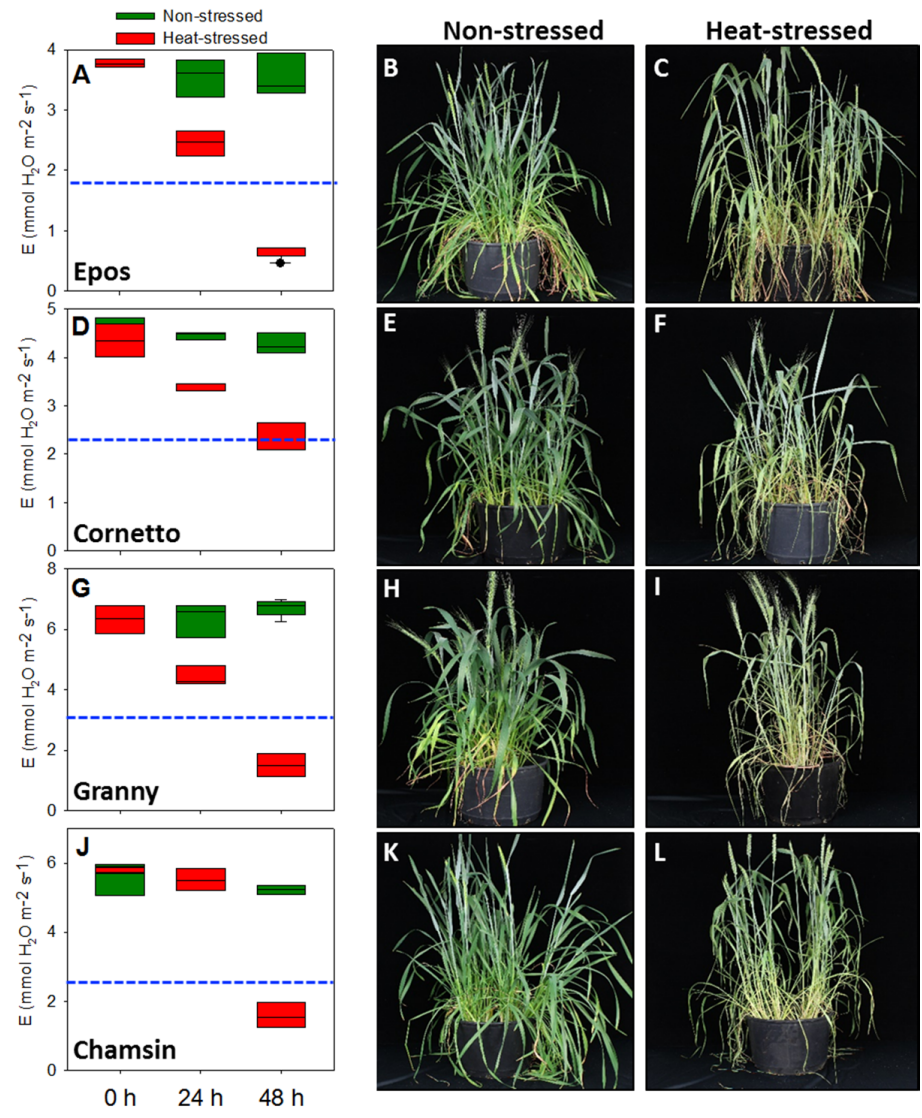

Figure 2. Moderate heat stress strongly alters transpiration rate of European summer wheat varieties. Physiological and phenotypical effects on varieties Epos (A-C), Cornetto (D-F), Granny (G-I), and Chamsin $(\mathbf{J}-\mathbf{L})$ are shown. Box plots show the central tendency and dispersion of the transpiration rate among all European cultivars. Green and red box plots represent non- and heat-stressed plants, respectively. Blue bars show $50 \%$ transpiration rate of non-stressed plants. $15-20$ plants of each line were examined.

\subsubsection{Photosynthesis Rate Was Strongly Reduced in European Cultivars}

Another physiological parameter highly affected by increased temperatures is the net photosynthetic rate. During stress treatment, a significant decline in gas exchange parameters occurred in all cultivars tested. However, a less accentuated drop was observed in the Australian cultivars (Figure 3A-D) compared with the European cultivars (Figure 3E,F). At $24 \mathrm{~h}$ after HS, photosynthesis remained close to the non-stress conditions in Kukri and Gladius as well as in Epos (Figure 3A,C,E). In Drysdale and Granny a decline of $22 \%$ and $25 \%$ on net photosynthesis were observed, respectively (Figure 3B,G). Notably, RAC875, Cornetto, and Chamsin showed a more pronounced decline, with a reduction of net photosynthetic levels of 55,60, and 77\%, respectively, relative to non-stressed control plants (Figure 3D,F,H). After 48 h of HS the Australian cultivars Kukri, Drysdale, and Gladius showed a higher tolerance to heat stress (Figure $3 \mathrm{~A}-\mathrm{C}$ ) as indicated by a higher photosynthetic activity. None of 
these cultivars showed a decrease below $50 \%$ of the photosynthetic rate under non-stress conditions. The photosynthetic rate of the fourth Australian cultivar tested (RAC875), declined close to 50\% already after $24 \mathrm{~h}$ of HS and remained at this value during continuation of HS treatment (Figure 3D). Unlike the Australian cultivars, European summer wheat cultivars with the exception of cultivar Epos were strongly affected already after $24 \mathrm{~h}$ of HS showing a sharp decline in photosynthesis rate (Figure 3E-H). In Cornetto and Chamsin (Figure 3F,H) a drop below $50 \%$ of the values observed under non-stress conditions was observed and in Granny (Figure 3G) to about $60 \%$ levels of control plants. After $48 \mathrm{~h}$ of HS exposure all European cultivars showed a net photosynthetic reduction of more than $75 \%$ reaching almost zero in Chamsin (Figure $3 \mathrm{H}$ ). In conclusion, two days after HS treatment, the net photosynthetic rate decreased on average over $80 \%$ in European cultivars, while none of the Australian cultivars showed a drop below 50\% compared to control plants. Two Australian cultivars (Kukri and Gladius) were especially well-adapted to HS and showed a drop of $25 \%$ in photosynthesis rate.

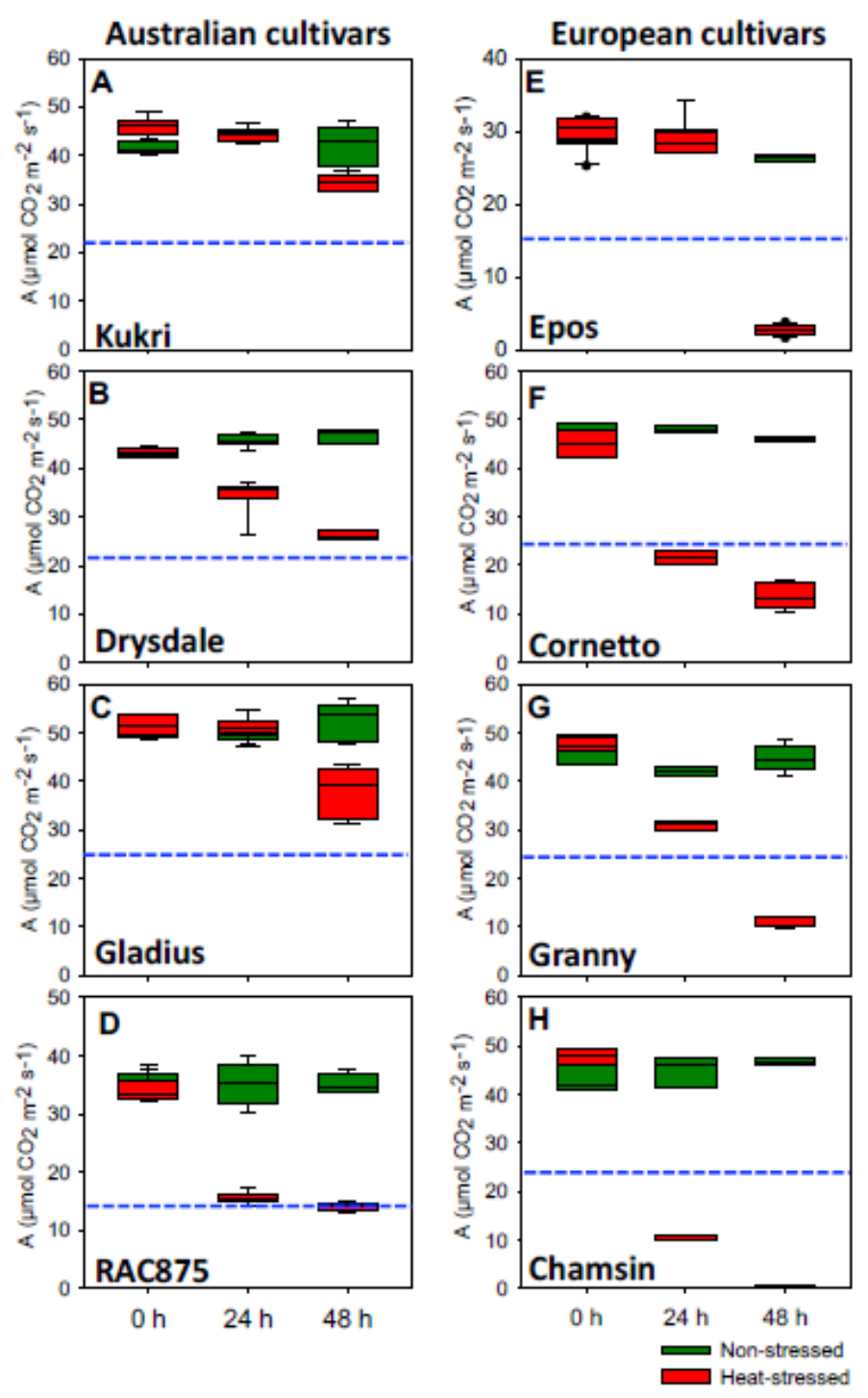

Figure 3. Effect of moderate heat stress on net photosynthesis rates of Australian (A-D) and European (E-H) summer wheat varieties during the pollen division stage. Box plots show the central tendency and dispersion of the net photosynthetic rate among all Australian and European wheat cultivars. Green and red box plots represent non- and heat-stressed plants, respectively. Blue bars show $50 \%$ net photosynthesis rates of non-stressed plants for comparison. 15-20 plants of each line were examined. 


\subsection{Analysis of Male Reproductive Structures after a Short-Term Moderate Heat Stress}

\subsubsection{Anther Morphology Was Not Significantly Modified after Moderate Heat Stress}

One of the most susceptible developmental stages to environmental stresses is male gametophyte development (pollen formation), which occurs in anthers. We collected anthers of all wheat cultivars under non-stress and heat-stress (HS) conditions (Figure S1). To illustrate how our histological analysis were carried out, a scheme indicating a wheat anther and its cross section is shown in Figure S1A. A schematic overview of the internal part of an anther is illustrated in Figure S1B and a detailed view explaining the various anther cell types in Figure S1C.

Under non-stress conditions, spikes containing anthers of both Australian and European cultivars were at the mitosis stage (Figure S1D-K). Identification of developmental stages was conducted based on the auricle distance, which is the distance between the auricles of the flag leaf and the second last leaf [33]. Spikes with an auricle distance between 13 and 15 centimeters were tagged and used for heat stress experiments; at this auricle distance, developing pollen grains completed meiosis and were at the microspore stage shortly before pollen mitosis. After two days of HS, Australian cultivars Kukri, Drysdale, Gladius, and RAC875 displayed normal anther and pollen development (Figure S1D-G). Notably, European wheat varieties also displayed normal pollen development both under HS and control conditions (Figure S1H,K). Pollen grains attached to the anthers were clearly noticeable. Overall, even though European cultivars were strongly affected at the physiological level, the morphology of male reproductive structures (anthers and pollen) did not appear to be severely affected.

\subsubsection{Pollen Viability Was Only Affected in European Cultivars after Moderate Heat Stress}

Decreased pollen viability has been reported as a major effect of heat stress during reproductive development. Even though anthers of Australian and European varieties did not show a significant damage after $48 \mathrm{~h}$ of heat stress (HS), we investigated to which extent pollen of both sets of plants were affected by HS. Pollen viability was tested using iodine-potassium (I2-IK) staining. As shown in Figure 4, almost all pollen grains from Australian varieties were viable (Figure 4A-D) as indicated by strong dyed starch coloration. On average $96-99 \%$ of pollen tested were viable (Figure 4I). In contrast, European wheat varieties exposed to HS had a significant amount of non-viable pollen grains, which either did not stain at all or were partially stained (Figure $4 \mathrm{E}-\mathrm{H}$ ). The most severe effect of HS was observed on pollen grains of the Epos cultivar (Figure 4E). Approximately $40 \%$ of pollen grains were non-viable (Figure $4 \mathrm{I})$. Similarly, around $25 \%$ of pollen grains from other European cultivars were non-viable. We could not test to which extent pollen germination and growth of viable pollen were affected, because wheat pollen generally germinate very poorly in vitro [38]. Nonetheless, our findings suggest that high temperatures during pollen development significantly impair pollen grain development of European cultivars, but not of Australian ones.

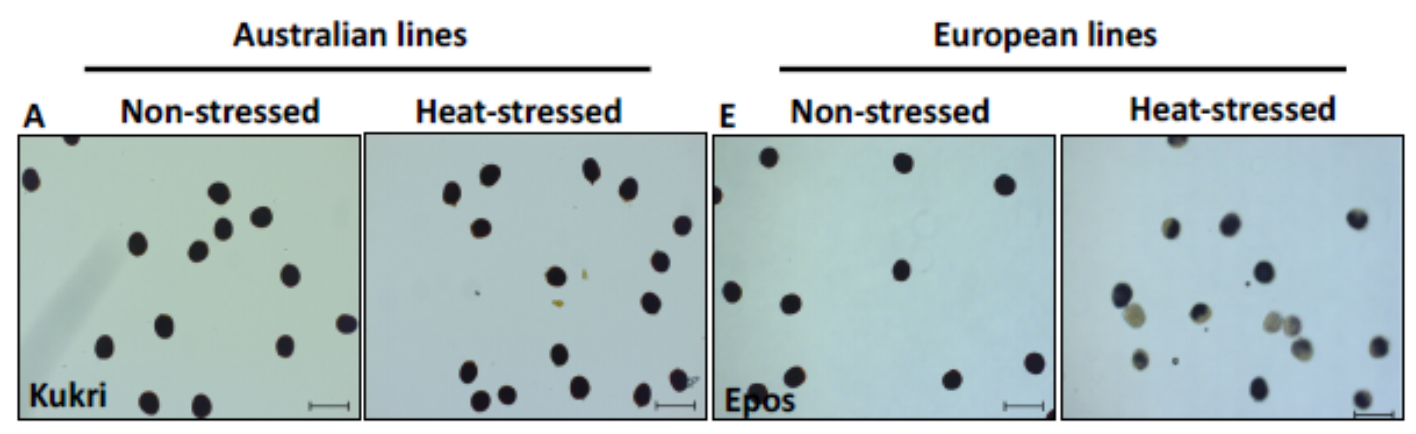

Figure 4. Cont. 

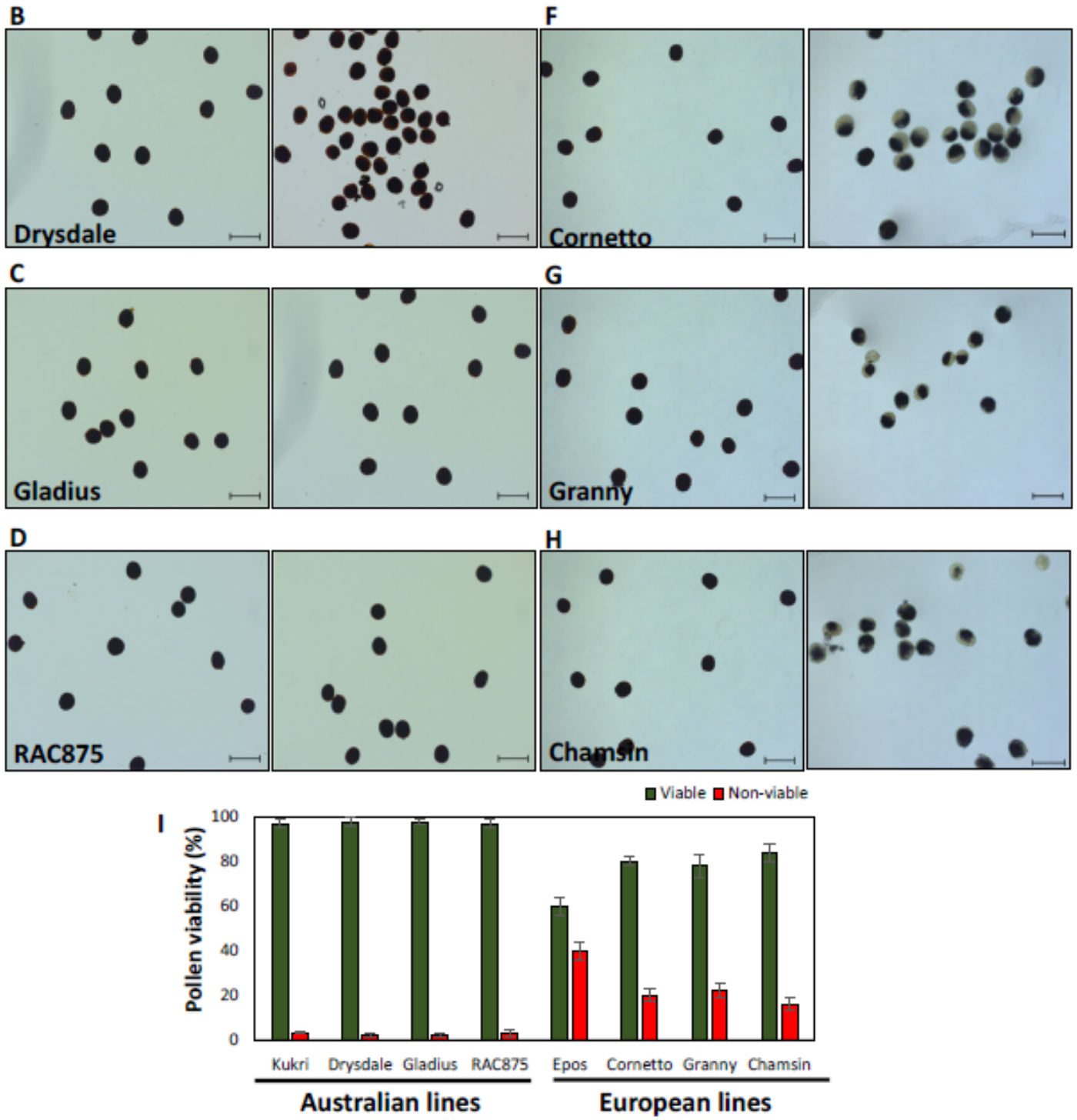

Figure 4. Pollen viability determined in Australian (A-D) and European (E-H) summer wheat varieties under non-stress and moderate heat-stress conditions. Pollen released from anthers were stained with lugol-iodine (I2-IK). (I) Percentage of viable pollen compared between Australian and Europeans summer wheat varieties after exposure to moderate heat stress during pollen mitosis.

\subsection{Heat Shock Factors Genes Were Strongly Regulated in European, but Not in Australian Cultivars}

In cereals and other plants, heat shock factors (HSFs) play an important regulatory role in response to heat stress (HS) and acquired thermotolerance. To understand the molecular basis of the HS response in Australian and European wheat cultivars, we analyzed and compared the gene expression level of several members of the HSF gene family. In wheat, 56 HSF genes have been identified, which were categorized into classes A, B, and C [17]. Many genes of the largest TaHSF class, A class, were previously shown to be predominately expressed in reproductive tissues under non-stress conditions [17]. Therefore, we selected this class to analyze their expression using anthers containing pollen at the mitosis stage under control and HS conditions.

TaHSF class A contains 25 genes divided into seven subclasses. As shown in Figure 5, all Australian cultivars responded to HS as indicated by significant up- and downregulation of some selected genes, while the relative expression levels of most genes were not dramatically altered. In Kukri only genes A3a, A3b, A4e, and A7e were strongly upregulated, while A6c, A6d, and A6e were strongly 
downregulated (Figure 5A). In Drysdale, the expression level of all other class A members remained low and invariable upon heat stress treatment (Figure 5B). Similarly, in Gladius, only five genes of subclass A6 were strongly downregulated with A6c and A6d even being completely switched off (Figure 5C). Interestingly, RAC875 showed a different response; subclasses A1 and A2 genes were upregulated after HS, while genes of the other subclasses were lowly expressed and did not alter their expression significantly after HS (Figure 5D). In general, class A HSF genes in the Australian wheat cultivars were similarly expressed both under HS and control conditions.
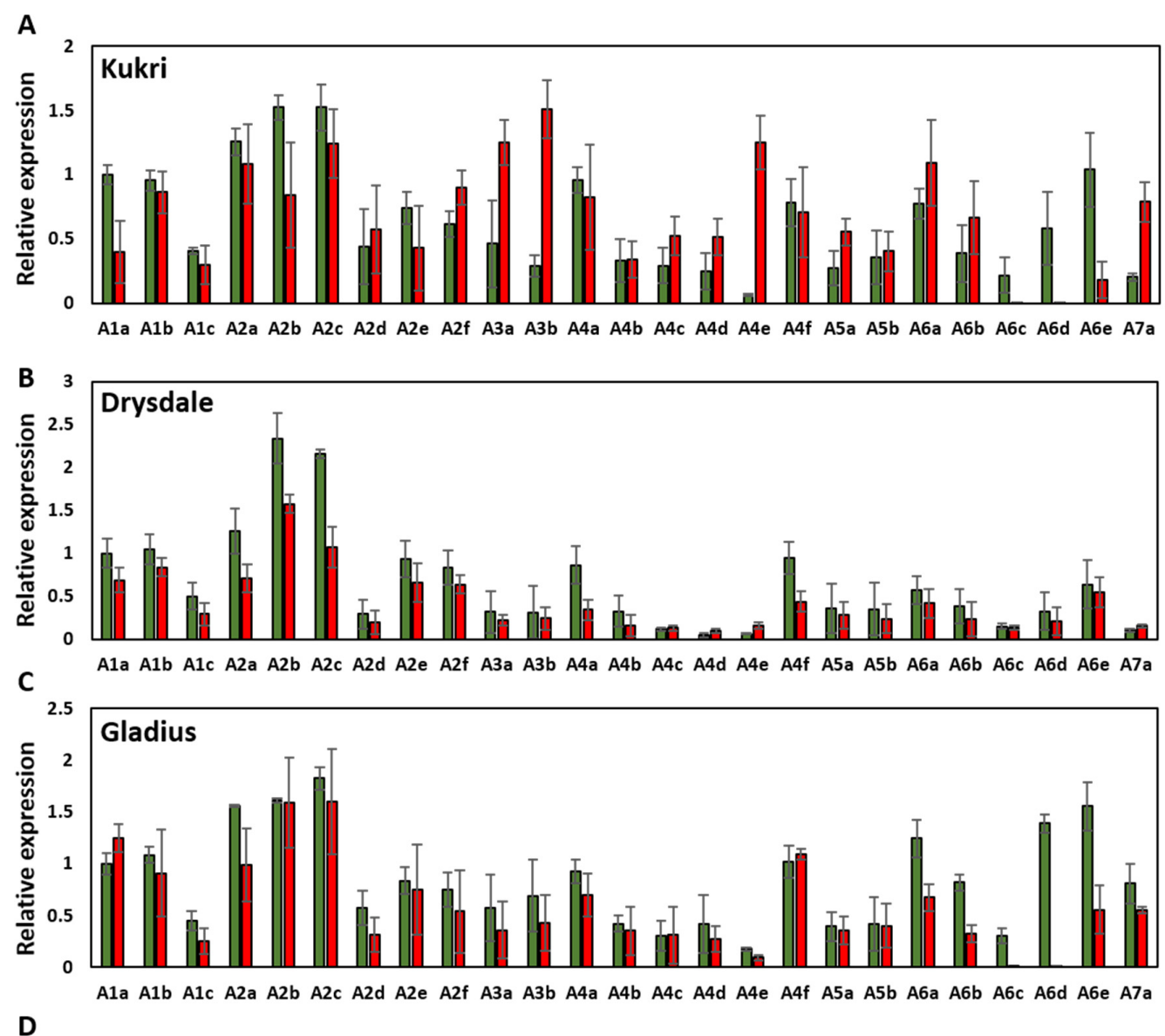

D

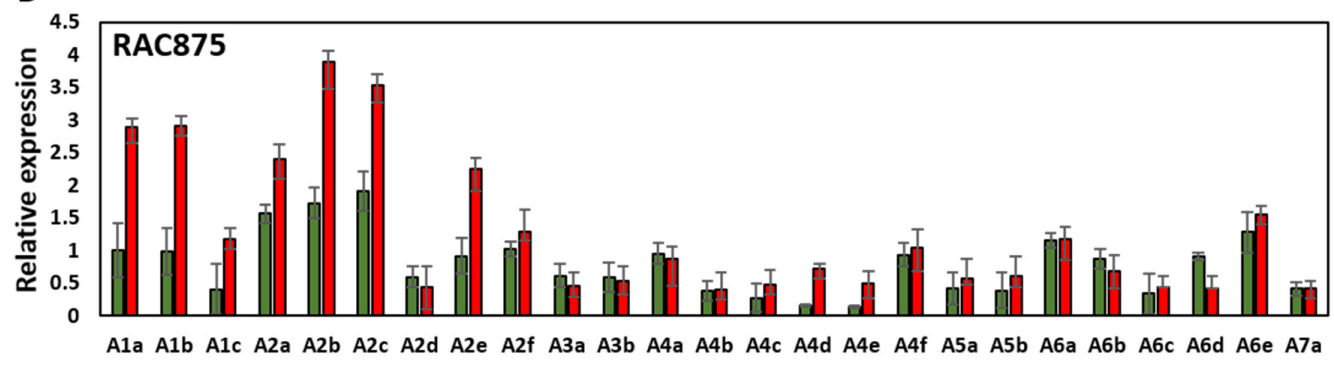

Figure 5. Relative mRNA expression levels of class A heat shock factor genes (TaHSFs) in anthers of Australian summer wheat varieties comparing heat stressed and control plants. A tubulin gene was used as a housekeeping gene for normalization. Expression values were set in relation to the average expression level of A1a HSF. Kukri (A), Drysdale (B), Gladius (C), and RAC875 (D). Green and red bars represent non- and heat-stressed plants, respectively. Values are means \pm SD of three biological replicates.

The European wheat cultivars showed a much stronger response to HS. In Epos, only HSF genes $\mathrm{A} 1 \mathrm{a}, \mathrm{A} 1 \mathrm{~b}, \mathrm{~A} 2 \mathrm{a}, \mathrm{A} 2 \mathrm{c}, \mathrm{A} 2 \mathrm{e}$, and A6a were expressed under non-stress conditions. With the exception 
of A6a, these genes were completely silenced after HS (Figure 6A). Similarly, Cornetto showed downregulation of almost all class A genes, except for A4e, which was upregulated, while A2a, A3a and A4f expression levels did not change significantly (Figure 6B). In Granny, low expression levels of HSFs were observed through the entire class A genes (Figure 6C). Under HS, with the exception of A2a, which showed comparable expression under non-stress conditions, all gene members of the subclasses A1 and A2 had low expression levels. Finally, Chamsin was the only European cultivar that showed a strong upregulation of HSF genes in response to HS. In general, class A HSF genes are expressed at low levels in this cultivar under non-stress conditions and a strong induction, especially of subclass A3 and A4 as well as of A2a was detected (Figure 6D). Taken together, our results indicate that the relatively stable transcriptional expression of HSF genes in the Australian cultivars is associated with their high level of acquired HS tolerance. Contrastingly, at the transcriptional level, the European cultivars showed a strong response in gene expression after HS exposure.
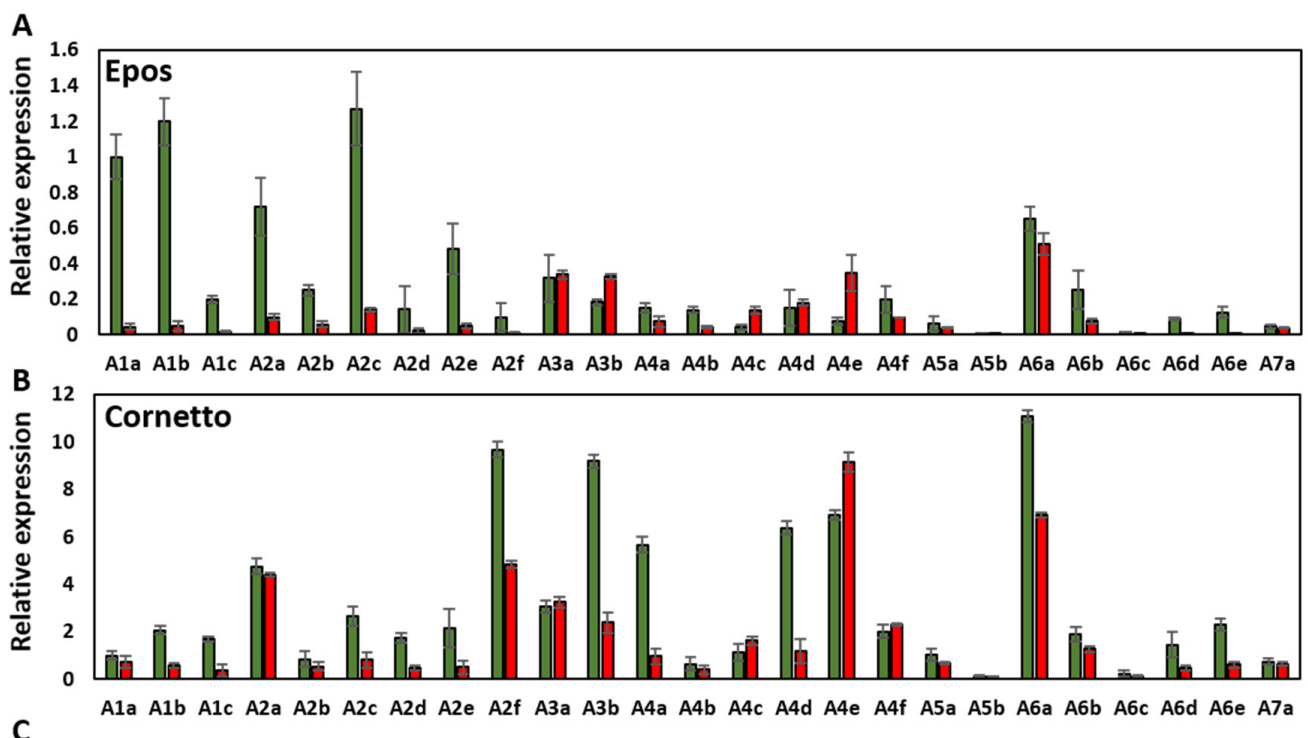

C
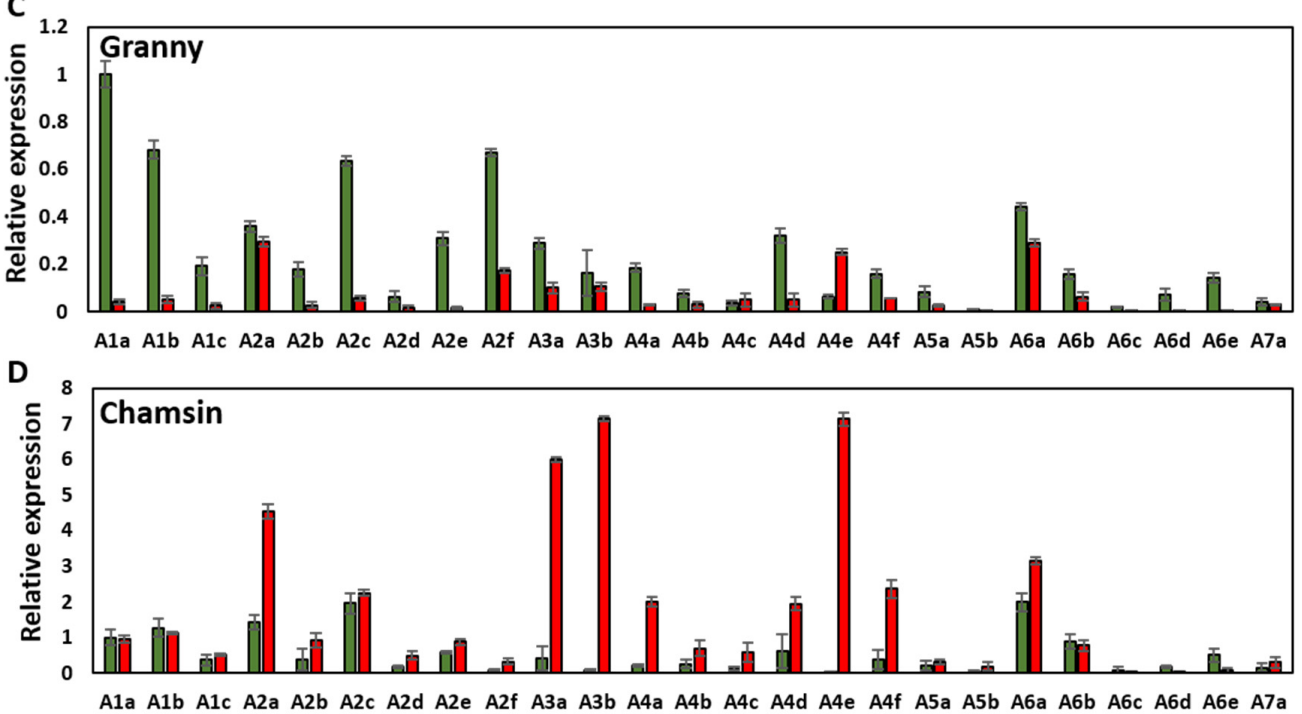

Figure 6. Relative mRNA expression levels of class A heat shock factor genes (TaHSFs) in anthers of European summer wheat varieties comparing heat stressed and control plants. A tubulin gene was used as housekeeping gene for normalization. Expression values were set in relation to the average expression level of A1a HSF. Epos (A), Cornetto (B), Granny (C), and Chamsin (D). Green and red bars represent non- and heat-stressed plants, respectively. Values are means \pm SD of three biological replicates. 


\section{Discussion}

The continuous improvement of wheat cultivars better adapted to environmental stresses, including increased temperatures, is an important goal of modern breeding and agriculture. To achieve this aim, it is necessary to comprehensively explore available germplasms to obtain a deeper understanding of the physiological and molecular adaptive mechanisms that differ between genotypes under changing environmental stress conditions. In this study, we analyzed two sets of summer wheat cultivars from different germplasms exposed to elevated temperatures. Our study confirms previous findings that long-term adaptation and breeding strategies have played fundamental roles in Australian wheat cultivars, which possess an enhanced tolerance to heat stress (HS) compared to European cultivars.

In general, plants use different strategies to overcome heat stress conditions. One of these strategies involves the adjustment between photosynthetic and transpiration rates through the regulation of stomata opening and closure. Stomata closure avoids the loss of water, but leads also to a reduction in $\mathrm{CO}_{2}$ assimilation and thus photosynthetic rate, while their opening increases gas exchange, including the uptake of $\mathrm{CO}_{2}$ and simultaneously to the cooling of the leaf surface at elevated temperatures. This avoids, for instance, membrane and thylakoid damage. Thus, a tight regulation is required to balance the various effects caused by increased temperatures [9]. Compared with HS susceptible European cultivars, we observed that Australian cultivars maintained higher photosynthetic and transpiration rates under moderate HS conditions. Similar observations have been made in tomato [12,13] and rice [14], where tolerant varieties displayed higher photosynthetic and transpiration rates compared to susceptible lines confirming our observations. The decline in these two gas exchange parameters as the result of HS has been suggested to be cultivar- and stage-dependent. Exposure of winter wheat cultivars to elevated temperatures resulted, for example, in a reduction of photosynthesis during the grain-filling phase compared to the vegetative stage [21,39]. Similarly, we found that all cultivars tested displayed an individual physiological and molecular HS response. Among the Australian summer wheat cultivars tested, Kukri and Gladius showed a relatively constant photosynthetic rate at increased temperatures, while Drysdale and RAC875 showed a significant decline. Natural variation in photosynthetic and transpiration rates are known to exist within crop species [40-43]. These variations have not shown a consistent correlation between photosynthetic rate during anthesis and grain yield or biomass when wheat cultivars were compared [40-43]. Particularly, wheat cultivars with the highest photosynthetic rates did not necessarily generate highest yields. Therefore, the large variation observed in Australian wheat cultivars could be attributed to unintentional selection traits that result in high photosynthetic rate [41,42]. Notably, Kukri, a drought-sensitive cultivar, and RAC875, a drought-tolerant one [44], displayed opposite responses to heat stress, indicating that these drought tolerant/susceptible Australian wheat cultivars display unrelated responses to heat stress. Similarly, a recent study showed large differences in gene expression responses to drought and heat stress between two barley cultivars [45] supporting this observation.

Unlike vegetative development, where stresses can be tolerated to a certain extent, reproductive development is highly sensitive to environmental stresses [18-20,34,45]. Male gametophyte or pollen development is especially susceptible to environmental stimuli, resulting in morphological, metabolic, and epigenetic alterations [23]. With the exception of a decrease in pollen viability in all European cultivars, we did not observe obvious alterations in anther and pollen morphology after HS. A moderate HS for two days is probably too short to cause more severe effects, which ultimately lead to complete sterility. Moreover, measuring the 100-grain weight and grain number per plant did not show significant differences when the heat stress was applied for only two days during the pollen mitosis stages (data not shown) and plants were allowed to quickly recover and grow at optimal conditions afterwards during the fertilization and seed filling stages. Thus the observed $20-40 \%$ loss in pollen viability in European cultivars could be compensated by viable pollen. A major future direction thus will be focused on investigating how longer HS periods affect sterility, seed set, and grain yield. Since starch, sugars, and other photoassimilates are generated during photosynthesis, a reduction in 
pollen viability detected in European cultivars could be linked to reduced photosynthetic activity and a reduction of photoassimilate transport to major sink organs, including anthers and pollen [22,46-48].

The ability of plants to respond to environmental stresses, especially to heat stress, is strongly associated with the integration of heat shock factors (HSFs), which are gene regulators of more elaborated responses [49]. Class A HSFs are the most abundant class of regulators and have been shown to be the main heat stress regulators in Arabidopsis [49] and tomato [50,51]. They also play a fundamental role in the regulation of abiotic stress responses in wheat [17]. Subclasses A1 and A2 genes that were predominantly expressed in all cultivars tested in our experiments, both under HS and control conditions, were also expressed in endosperm samples of spring wheat cultivar Bobwhite [17]. This indicates a preferential expression of these genes during reproductive development. In heat-stressed tomato anthers, A2 HSF members were highly induced under moderate and severe heat stress conditions. Their high expression levels were maintained even after several days of the stress treatment [51]. Expression levels of European summer wheat cultivars were generally lower and responses more variable compared to the Australian cultivars. For instance, in Epos, one of the most susceptible cultivars to HS, almost all HSF class A genes were strongly downregulated by heat stress, indicating a low sustained response to increased temperatures. Cultivars like Chamsin strongly induce HSF genes ultimately leading to a complete switch off of net photosynthesis.

\section{Conclusions}

In conclusion, HSF genes appear to be already expressed at substantial levels in HS tolerant wheat cultivars such as the Australian ones used in this study. In contrast, European cultivars showed lower expression levels under non-stress conditions and in most cultivars even a further reduced expression after exposure to moderate HS. By increasing the basal expression level of HSF genes, either by genetic engineering or by selecting corresponding wheat lines during breeding programs, we assume that better wheat germplasm can be generated to ameliorate adaptation to increased temperatures. This will also be relevant for short and transient heat waves occurring during reproductive development, as especially male flower organs as well as pollen development are very sensitive to elevated temperatures. A key approach will be a systematic analysis of the regulation of HSF genes, but how does HS lead to the complete silencing of HSF genes in some cultivars, while others show a strong upregulation or even de novo induction of gene expression? The European cultivars Epos and Chamsin are very suitable to address these interesting questions in future studies.

Supplementary Materials: The following are available online at http://www.mdpi.com/2073-4395/8/7/99/s1.

Author Contributions: K.B. and T.D. conceived the experiments. K.B., A.W. and A.O.E. performed the experiments. K.B. and T.D. analyzed the data and wrote the manuscript. All authors read and approved the manuscript.

Funding: This work was supported by the BayKlimaFit program of the Bavarian State Ministry of the Environment and Consumer Protection (Grant No. 810100). AOE was a recipient of a short-term research scholarship from the German Academic Exchange Service (DAAD) (Grant No. 57349843).

Acknowledgments: We acknowledge Peter Langridge (University of Adelaide), Hubert Kempf (Secobra Saatzucht $\mathrm{GmbH}$ ), and Uwe Stephan (Saatzucht Bauer $\mathrm{GmbH}$ ) for providing a large number of summer wheat cultivars, of which eight were finally selected for this study. We thank Noureddine Djella and Armin Hildebrand for plant care.

Conflicts of Interest: The authors declare no conflict of interest.

\section{References}

1. Shiferaw, B.; Smale, M.; Braun, H.J.; Duveiller, E.; Reynolds, M.; Muricho, G. Crops that feed the world 10. Past successes and future challenges to the role played by wheat in global food security. Food Secur. 2013, 5, 291-317. [CrossRef]

2. Shewry, P.R. Wheat. J. Exp. Bot. 2009, 60, 1537-1553. [CrossRef] [PubMed] 
3. Vergauwen, D.; De Smet, I. From early farmers to Norman Borlaug—The making of modern wheat. Curr. Biol. 2017, 27, R858-R862. [CrossRef] [PubMed]

4. Zheng, B.Y.; Chenu, K.; Dreccer, M.F.; Chapman, S.C. Breeding for the future: What are the potential impacts of future frost and heat events on sowing and flowering time requirements for Australian bread wheat (Triticum aestivium) varieties? Glob. Chang. Biol. 2012, 18, 2899-2914. [CrossRef] [PubMed]

5. USDA Foreign Agriculture Service. Wheat: World Markets and Trade; Office of Global Analysis-USDA: Washington, DC, USA, 2018.

6. Agricultural Production-Crops; Eurostat: Luxembourg, 2017.

7. Joukhadar, R.; Daetwyler, H.D.; Bansal, U.K.; Gendall, A.R.; Hayden, M.J. Genetic diversity, population structure and ancestral origin of Australian wheat. Front. Plant Sci. 2017, 8, 2115. [CrossRef] [PubMed]

8. Wieland, T. Scientific theory and agricultural practice: Plant breeding in Germany from the late 19th to the early 20th century. J. Hist. Biol. 2006, 39, 309-343. [CrossRef]

9. Sharkey, T.D. Effects of moderate heat stress on photosynthesis: Importance of thylakoid reactions, rubisco deactivation, reactive oxygen species, and thermotolerance provided by isoprene. Plant Cell Environ. 2005, 28, 269-277. [CrossRef]

10. Kobza, J.; Edwards, G.E. Influences of leaf temperature on photosynthetic carbon metabolism in wheat. Plant Physiol. 1987, 83, 69-74. [CrossRef] [PubMed]

11. Weis, E. Reversible heat-inactivation of the Calvin Cycle-A possible mechanism of the temperature regulation of photosynthesis. Planta 1981, 51, 33-39. [CrossRef] [PubMed]

12. Camejo, D.; Rodriguez, P.; Morales, A.; Dell'Amico, J.M.; Torrecillas, A.; Alarcon, J.J. High temperature effects on photosynthetic activity of two tomato cultivars with different heat susceptibility. J. Plant Physiol. 2005, 162, 281-289. [CrossRef] [PubMed]

13. Zhou, R.; Yu, X.Q.; Kjaer, K.H.; Rosenqvist, E.; Ottosen, C.O.; Wu, Z. Screening and validation of tomato genotypes under heat stress using F-v/F-m to reveal the physiological mechanism of heat tolerance. Environ. Exp. Bot. 2015, 118, 1-11. [CrossRef]

14. Sailaja, B.; Subrahmanyam, D.; Neelamraju, S.; Vishnukiran, T.; Rao, Y.V.; Vijayalakshmi, P.; Voleti, S.R.; Bhadana, V.P.; Mangrauthia, S.K. Integrated physiological, biochemical, and molecular analysis identifies important traits and mechanisms associated with differential response of rice genotypes to elevated temperature. Front. Plant Sci. 2015, 6, 1044. [CrossRef] [PubMed]

15. Scharf, K.D.; Berberich, T.; Ebersberger, I.; Nover, L. The plant heat stress transcription factor (Hsf) family: Structure, function and evolution. Biochim. Biophys. Acta 2012, 1819, 104-119. [CrossRef] [PubMed]

16. Mishra, S.K.; Tripp, J.; Winkelhaus, S.; Tschiersch, B.; Theres, K.; Nover, L.; Scharf, K.D. In the complex family of heat stress transcription factors, HSfA1 has a unique role as master regulator of thermotolerance in tomato. Genes Dev. 2002, 16, 1555-1567. [CrossRef] [PubMed]

17. Xue, G.P.; Sadat, S.; Drenth, J.; McIntyre, C.L. The heat shock factor family from Triticum aestivum in response to heat and other major abiotic stresses and their role in regulation of heat shock protein genes. J. Exp. Bot. 2014, 65, 539-557. [CrossRef] [PubMed]

18. Begcy, K.; Dresselhaus, T. Epigenetic responses to abiotic stresses during reproductive development in cereals. Plant Reprod. 2018, 31. [CrossRef]

19. Chen, C.; Begcy, K.; Liu, K.; Folsom, J.J.; Wang, Z.; Zhang, C.; Walia, H. Heat stress yields a unique MADS box transcription factor in determining seed size and thermal sensitivity. Plant Physiol. 2016, 171, 606-622. [CrossRef] [PubMed]

20. Folsom, J.J.; Begcy, K.; Hao, X.; Wang, D.; Walia, H. Rice Fertilization-Independent Endosperm1 regulates seed size under heat stress by controlling early endosperm development. Plant Physiol. 2014, 165, 238-248. [CrossRef] [PubMed]

21. Monneveux, P.; Pastenes, C.; Reynolds, M.P. Limitations to photosynthesis under light and heat stress in three high-yielding wheat genotypes. J. Plant Physiol. 2003, 160, 657-666. [CrossRef] [PubMed]

22. De Storme, N.; Geelen, D. The impact of environmental stress on male reproductive development in plants: Biological processes and molecular mechanisms. Plant Cell Environ. 2014, 37, 1-18. [CrossRef] [PubMed]

23. Gomez, J.F.; Talle, B.; Wilson, Z.A. Anther and pollen development: A conserved developmental pathway. J. Integr. Plant Biol. 2015, 57, 876-891. [CrossRef] [PubMed]

24. Wilson, Z.A.; Zhang, D.B. From Arabidopsis to rice: Pathways in pollen development. J. Exp. Bot. 2009, 60, 1479-1492. [CrossRef] [PubMed] 
25. Begcy, K.; Dresselhaus, T. Tracking maize pollen development by the Leaf Collar Method. Plant Reprod. 2017, 30, 171-178. [CrossRef] [PubMed]

26. Chakrabarti, B.; Singh, S.D.; Nagarajan, S.; Aggarwal, P.K. Impact of temperature on phenology and pollen sterility of wheat varieties. Aust. J. Crop Sci. 2011, 5, 1039-1043.

27. Hlavacova, M.; Klem, K.; Smutna, P.; Skarpa, P.; Hlavinka, P.; Novotna, K.; Rapantova, B.; Trnka, M. Effect of heat stress at anthesis on yield formation in winter wheat. Plant Soil Environ. 2017, 63, 139-144.

28. Omidi, M.; Siahpoosh, M.R.; Mamghani, R.; Modarresi, M. The influence of terminal heat stress on meiosis abnormalities in pollen mother cells of wheat. Cytologia 2014, 79, 49-58. [CrossRef]

29. Pradhan, G.P.; Prasad, P.V.V.; Fritz, A.K.; Kirkham, M.B.; Gill, B.S. Effects of drought and high temperature stress on synthetic hexaploid wheat. Funct. Plant Biol. 2012, 39, 190-198. [CrossRef]

30. Liu, B.; Asseng, S.; Liu, L.L.; Tang, L.; Cao, W.X.; Zhu, Y. Testing the responses of four wheat crop models to heat stress at anthesis and grain filling. Glob. Chang. Biol. 2016, 22, 1890-1903. [CrossRef] [PubMed]

31. Farooq, M.; Bramley, H.; Palta, J.A.; Siddique, K.H.M. Heat stress in wheat during reproductive and grain-filling phases. Crit. Rev. Plant Sci. 2011, 30, 491-507. [CrossRef]

32. Ji, X.; Shiran, B.; Wan, J.; Lewis, D.C.; Jenkins, C.L.; Condon, A.G.; Richards, R.A.; Dolferus, R. Importance of pre-anthesis anther sink strength for maintenance of grain number during reproductive stage water stress in wheat. Plant Cell Environ. 2010, 33, 926-942. [CrossRef] [PubMed]

33. Begcy, K.; Mariano, E.D.; Gentile, A.; Lembke, C.G.; Zingaretti, S.M.; Souza, G.M.; Menossi, M. A novel stress-induced sugarcane gene confers tolerance to drought, salt and oxidative stress in transgenic tobacco plants. PLoS ONE 2012, 7, e44697. [CrossRef] [PubMed]

34. Mattiello, L.; Begcy, K.; da Silva, F.R.; Jorge, R.A.; Menossi, M. Transcriptome analysis highlights changes in the leaves of maize plants cultivated in acidic soil containing toxic levels of $\mathrm{Al}\left({ }^{3+}\right)$. Mol. Biol. Rep. 2014, 41, 8107-8116. [CrossRef] [PubMed]

35. Begcy, K.; Walia, H. Drought stress delays endosperm development and misregulates genes associated with cytoskeleton organization and grain quality proteins in developing wheat seeds. Plant Sci. 2015, 240, 109-119. [CrossRef] [PubMed]

36. Livak, K.J.; Schmittgen, T.D. Analysis of relative gene expression data using real-time quantitative PCR and the 2(T)(-Delta Delta C) method. Methods 2001, 25, 402-408. [CrossRef] [PubMed]

37. Sinsawat, V.; Leipner, J.; Stamp, P.; Fracheboud, Y. Effect of heat stress on the photosynthetic apparatus in maize (Zea mays L.) grown at control or high temperature. Environ. Exp. Bot. 2004, 52, 123-129. [CrossRef]

38. Cheng, C.H.; Mccomb, J.A. In vitro germination of wheat pollen on raffinose medium. New Phytol. 1992, 120, 459-462. [CrossRef]

39. Feng, B.; Liu, P.; Li, G.; Dong, S.T.; Wang, F.H.; Kong, L.A.; Zhang, J.W. Effect of heat stress on the photosynthetic characteristics in flag leaves at the grain-filling stage of different heat-resistant winter wheat varieties. J. Agron. Crop Sci. 2014, 200, 143-155. [CrossRef]

40. Chytyk, C.J.; Hucl, P.J.; Gray, G.R. Leaf photosynthetic properties and biomass accumulation of selected western Canadian spring wheat cultivars. Can. J. Plant Sci. 2011, 91, 305-314. [CrossRef]

41. Driever, S.M.; Lawson, T.; Andralojc, P.J.; Raines, C.A.; Parry, M.A.J. Natural variation in photosynthetic capacity, growth, and yield in 64 field-grown wheat genotypes. J. Exp. Bot. 2014, 65, 4959-4973. [CrossRef] [PubMed]

42. Jackson, P.; Basnayake, J.; Inman-Bamber, G.; Lakshmanan, P.; Natarajan, S.; Stokes, C. Genetic variation in transpiration efficiency and relationships between whole plant and leaf gas exchange measurements in Saccharum spp. and related germplasm. J. Exp. Bot. 2016, 67, 861-871. [CrossRef] [PubMed]

43. Sadras, V.O.; Lawson, C.; Montoro, A. Photosynthetic traits in Australian wheat varieties released between 1958 and 2007. Field Crop Res. 2012, 134, 19-29. [CrossRef]

44. Ford, K.L.; Cassin, A.; Bacic, A. Quantitative proteomic analysis of wheat cultivars with differing drought stress tolerance. Front. Plant Sci. 2011, 2, 44. [CrossRef] [PubMed]

45. Cantalapiedra, C.P.; Garcia-Pereira, M.J.; Gracia, M.P.; Igartua, E.; Casas, A.M.; Contreras-Moreira, B. Large differences in gene expression responses to drought and heat stress between elite barley cultivar Scarlett and a spanish landrace. Front. Plant Sci. 2017, 8, 647. [CrossRef] [PubMed]

46. Barnabas, B.; Jager, K.; Feher, A. The effect of drought and heat stress on reproductive processes in cereals. Plant Cell Environ. 2008, 31, 11-38. [CrossRef] [PubMed] 
47. Dai, Z.W.; Wang, L.J.; Zhao, J.Y.; Fan, P.G.; Li, S.H. Effect and after-effect of water stress on the distribution of newly-fixed C-14-photoassimilate in micropropagated apple plants. Environ. Exp. Bot. 2007, 60, 484-494. [CrossRef]

48. Sudhir, P.; Murthy, S.D.S. Effects of salt stress on basic processes of photosynthesis. Photosynthetica 2004, 42, 481-486. [CrossRef]

49. Guo, M.; Liu, J.H.; Ma, X.; Luo, D.X.; Gong, Z.H.; Lu, M.H. The plant heat stress transcription factors (HSFs): Structure, regulation, and function in response to abiotic stresses. Front. Plant Sci. 2016, 7, 114. [CrossRef] [PubMed]

50. Bharti, K.; von Koskull-Doring, P.; Bharti, S.; Kumar, P.; Tintschl-Korbitzer, A.; Treuter, E.; Nover, L. Tomato heat stress transcription factor HsfB1 represents a novel type of general transcription coactivator with a histone-like motif interacting with the plant CREB binding protein ortholog HAC1. Plant Cell 2004, 16, 1521-1535. [CrossRef] [PubMed]

51. Giorno, F.; Wolters-Arts, M.; Grillo, S.; Scharf, K.D.; Vriezen, W.H.; Mariani, C. Developmental and heat stress-regulated expression of HsfA2 and small heat shock proteins in tomato anthers. J. Exp. Bot. 2010, 61, 453-462. [CrossRef] [PubMed]

(C) 2018 by the authors. Licensee MDPI, Basel, Switzerland. This article is an open access article distributed under the terms and conditions of the Creative Commons Attribution (CC BY) license (http://creativecommons.org/licenses/by/4.0/). 